\title{
Analysis on the demand and cultivation of the international technical standardized talents
}

\author{
Jing Yin ${ }^{1, a}$ \\ ${ }^{1}$ Beijing University of Civil Engineering and Architecture, Beijing, China, 100044 \\ anjy2001@163.com
}

Keywords: international standardized talents, technical standards, standardized education.

\begin{abstract}
Facing with the challenges of the technology standard internationalization, it is necessary to cultivate a large number of standardized professional talents in different levels and fields as soon as possible, especially the high-quality talents. The competition and the challenges of international standards under WTO are analyzed. On the basis, the talent demand can be inferenced. At last, the cultivate scheme and system content settings are proposed.
\end{abstract}

\section{Introduction}

With the accelerating process of global economic integration, technology standard has become a new tool for the international competition, currently showing the coexist situation of internationalization development in depth and regional difference diversity. Currently, it is the focus of all countries in the world to know how to get the control and the initiative in the fierce competition of international standards, and how to master the discourse power of the international market. Therefore, it has a very important strategic significance to improve the education system and establish the training program for international standardized talents as soon as possible.

\section{Competition of international standards under WTO}

WTO technical trade barriers. At present, the technical trade barriers based on the core content of the standard has become a great concern of the world. The developed countries have the technical standards as one of the strategies aimed at international trade, and strive to reflect the interests of the country in the international standard requirements. According to the statistics of WTO data, the technical trade barrier notification submitted by WTO members as shown in Fig. 1.

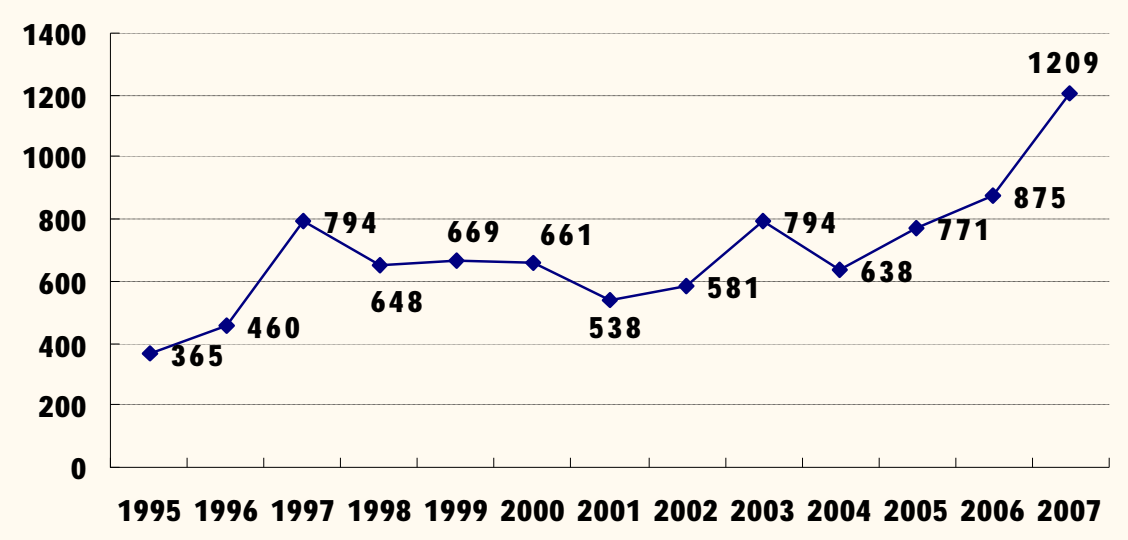

Fig. 1 Notification submitted by WTO member

\section{International standardization activities}

Mainly developed countries will control for strategic high ground as the core goal, specific performance in undertaking the international organization for standardization secretariat, led the 
development of international standards, undertake the chairman, vice chairman of international group. At present, the international standardization activities of the countries are shown as fig.2- fig.5.

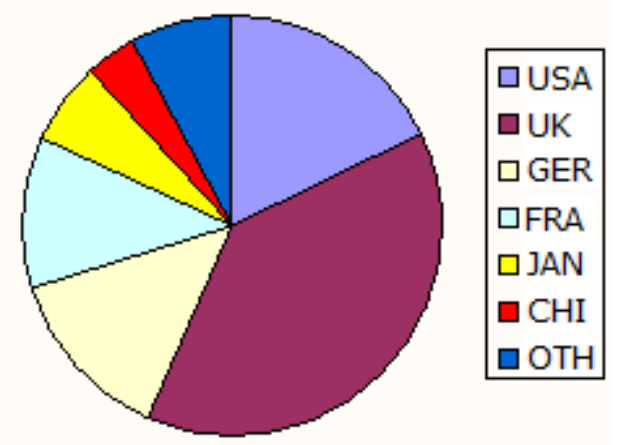

Fig.2 Undertakeing the secretariat of ISO、 IEC

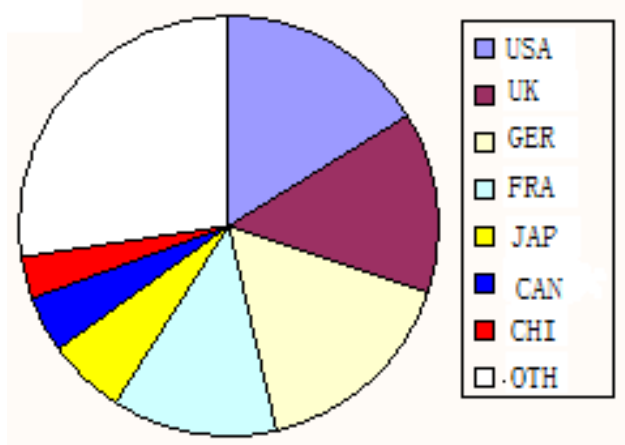

Fig.4 Undertakeing the Chairman of ISO/TC

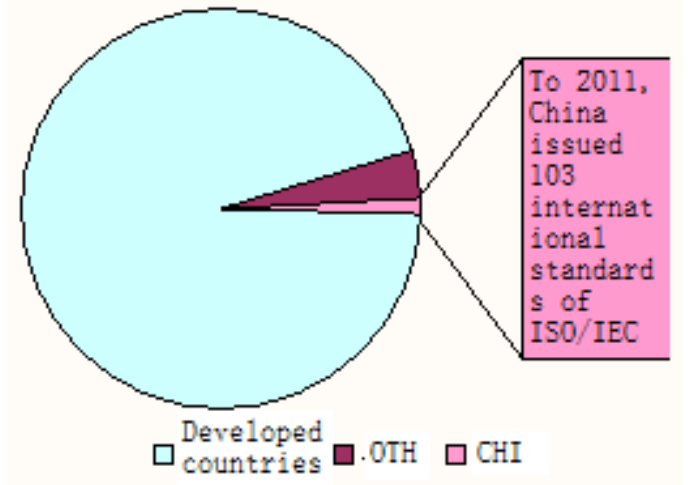

Fig.3 Leading the development of international standards

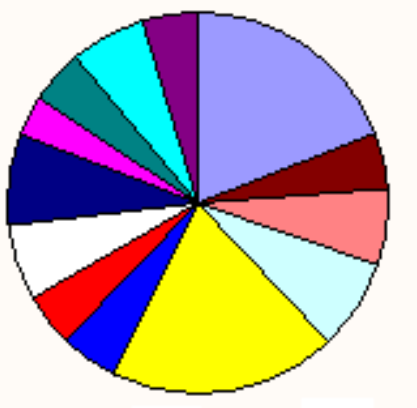

$\begin{array}{llll}\square \text { USA } & \square \text { UK } & \square \text { GER } & \square \text { FRA } \\ \square \text { JAP } & \square \text { CAN } & \square \text { SGP } & \square \text { IND } \\ \square \text { ITA } & \square \text { BRA } & \square \text { USSR } & \square \text { AUS } \\ \square \text { SUI } & & & \end{array}$

Fig. 5 Period of Undertakeing the Chairman of ISO、IEC

From the available data, we can see the number of the standardization activities our country participated in the international organization by our country is increasing year by year. However, there are still relatively few and mainly involved in the activities such as literature tracking, data retrieval, vote on specific issues and etc. The core activities, such as the international standard set, undertake the chairman and etc., need to enhance discourse right and substantive participation ability.

challenges of China's standard internationalization

Low adoption rate

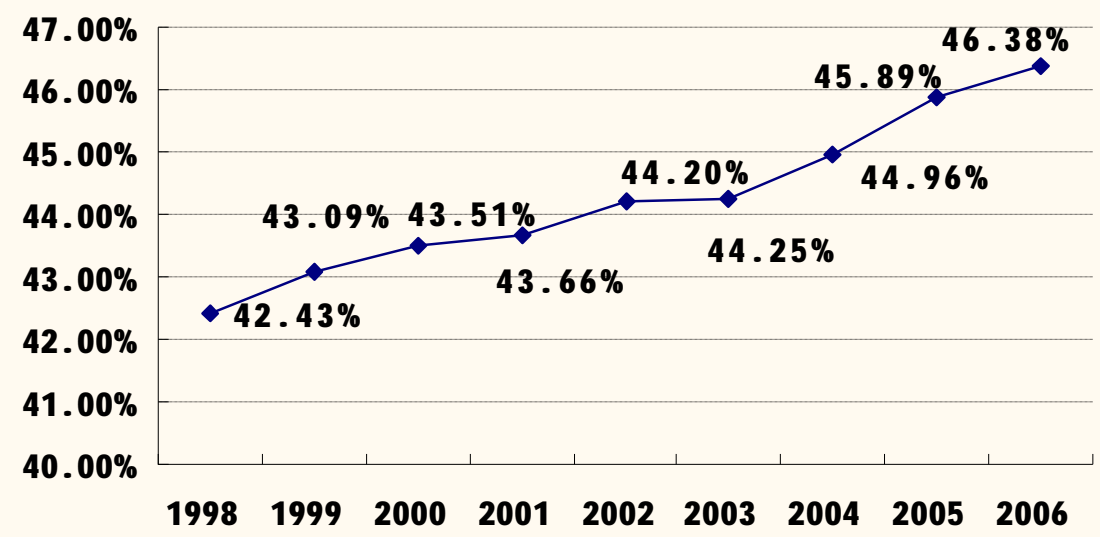

Long cycle of the current national standards development 


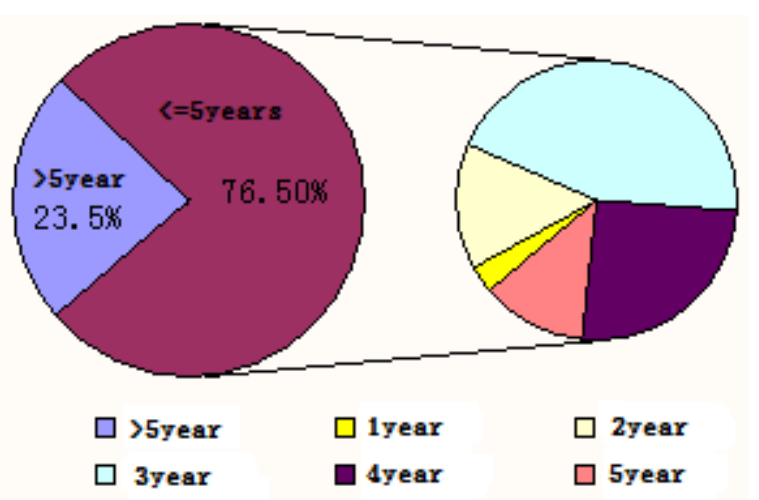

Fig.7 cycle of the current national standards development

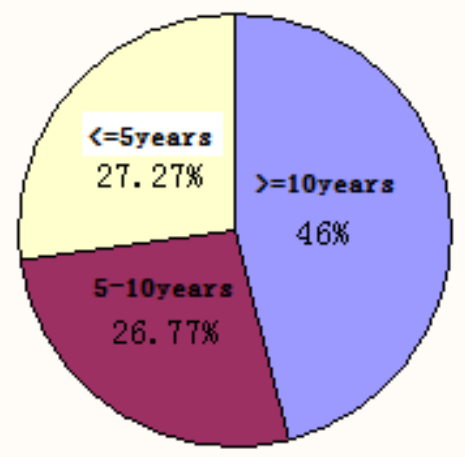

Fig.8 Current national standard age

\section{Serious shortage of international standardization talents}

As the development backbone of the national standards, the growing of standardization organization in china support the rapid development of national standardization. The number of national standardization technical organization of TC, SC and WG in china is more than 700. The main staff and distribution are shown as Fig.9- Fig.10

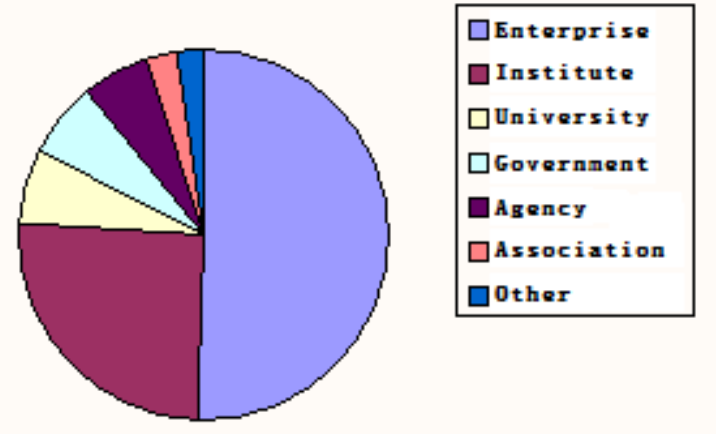

Fig.9 Distribution of the national standardization staff

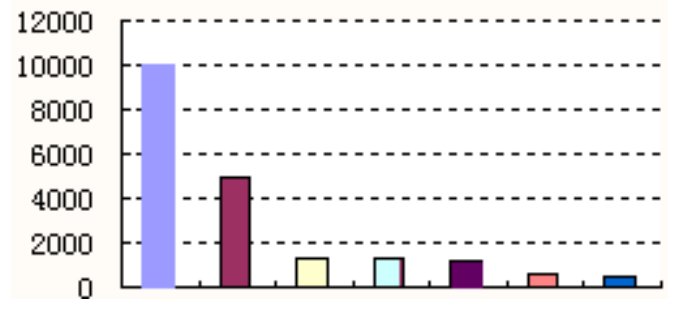

Fig.10 Quantity of the national standardization staff

From the above, it can be seen that the standardized professional team has been formed that composed of the standardization institute, universities, government, enterprises, inspection agency and etc. However, the number of the existing standardized professional staff in our country is still very limited and the high level talent ratio can not be compared with the developed countries. Facing with the challenges of the technology standard internationalization, it is necessary to cultivate a large number of standardized professional talents in different levels and fields as soon as possible, especially the high-quality talents who can represent the country or enterprises to participate in international standards. It is a very important and urgent strategic task for our country to cultivate high-quality international standardization personnel and provide the talent guarantee for the realization of my technical standard development strategy.

\section{Cultivate scheme and content settings}

Based on the analysis above, focusing on the cultivating of international standardization talents, the Cultivate scheme and content settings are proposed and shown as Fig.11- Fig.12. It mainly includs the works such as the analysis and research of international standards, key projects in domain and abroad, international standards advisory services, international certification implementation, international exchanges and cooperation, and other key work. 


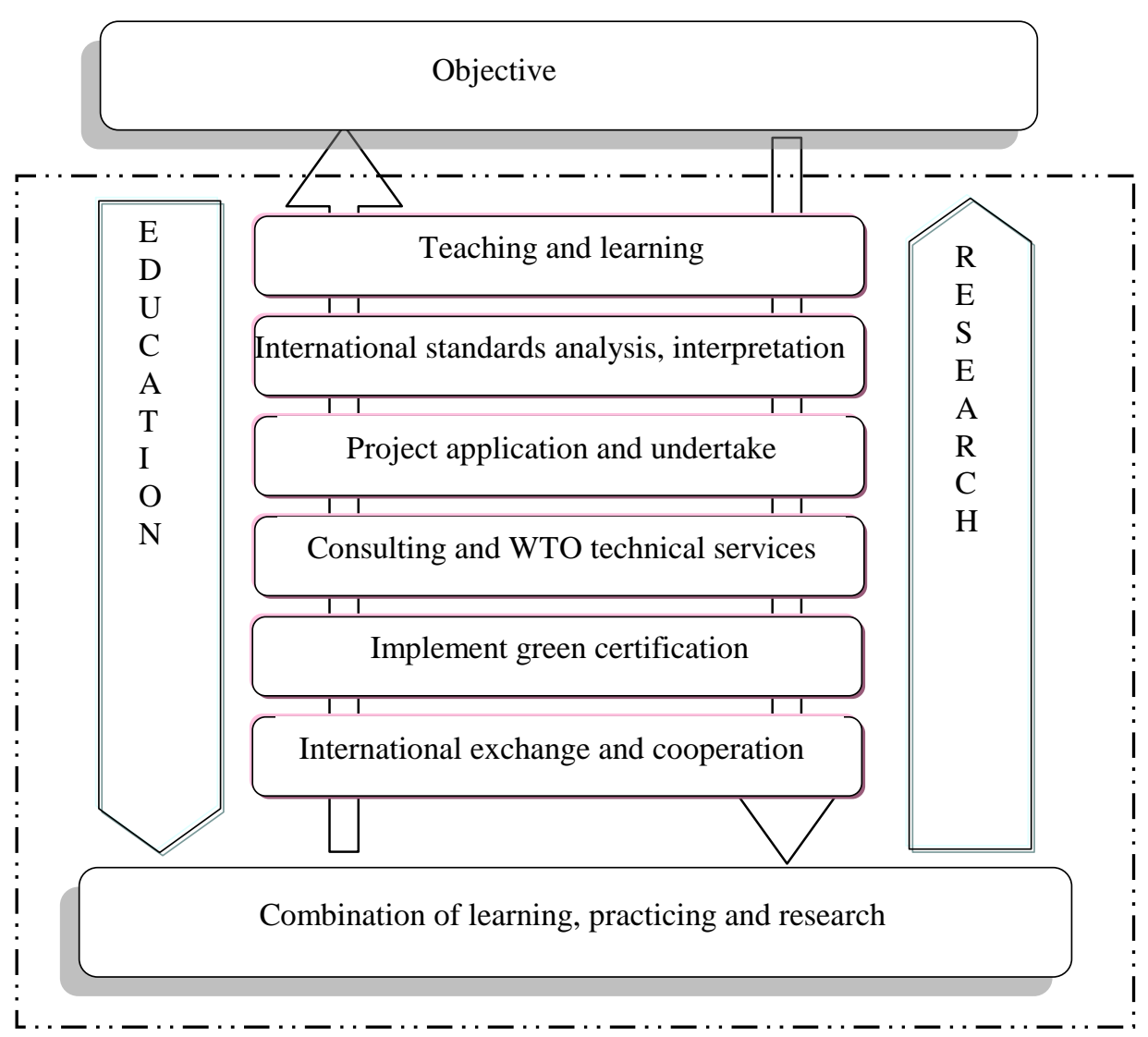

\section{Content of education and training}

Fig.11 Cultivate scheme

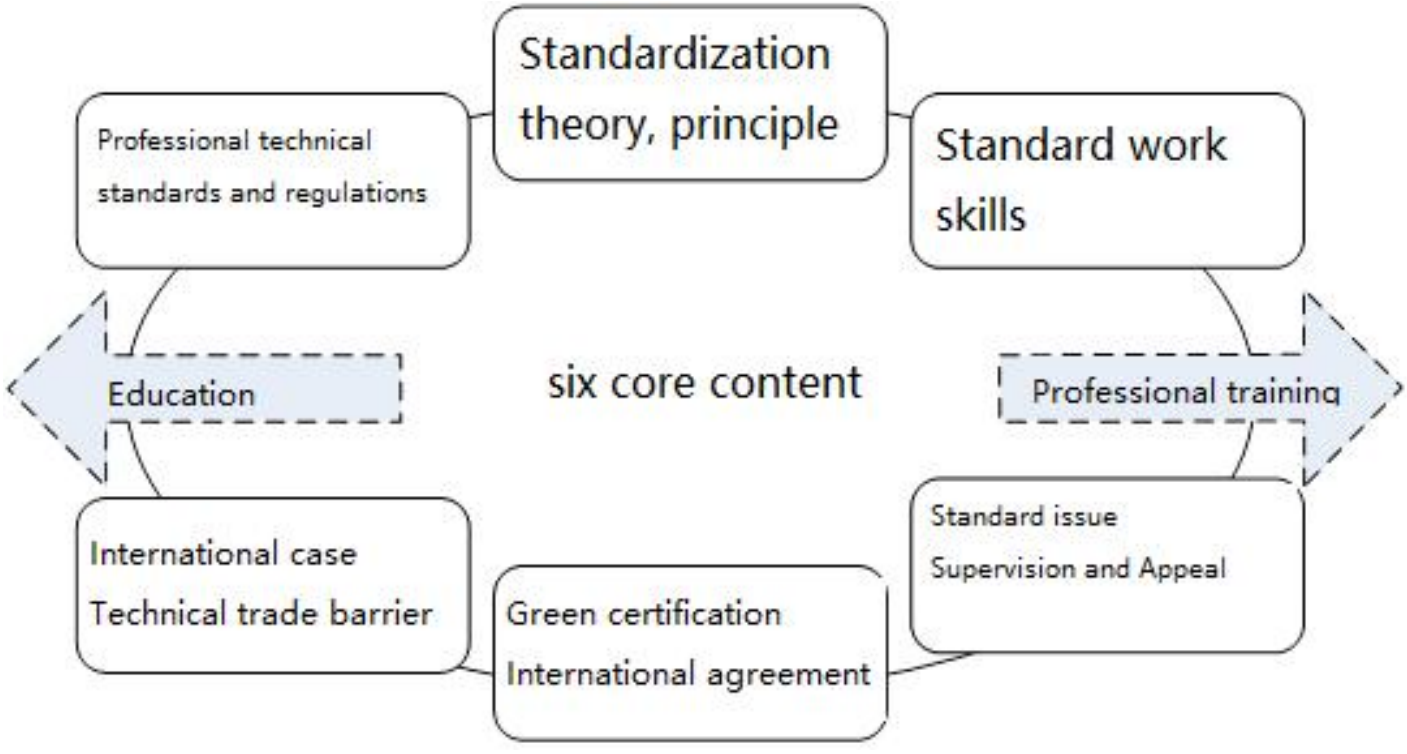

Fig.12 Cultivate system and content

\section{References}

[1] Li Dongqing. Problems and Countermeasures of Chinese standardized personnel training. Research on Higher Engineering Education ,2012,6.

[2] Wang Jianmin, Xu Dongbei. Research on the training system of standardized talents based on Competency Model. Standard science,2014,5. 